\title{
Aminoglycoside-induced ototoxicity
}

\author{
Jerome A. Leis MD MSc, John A. Rutka MD, Wayne L. Gold MD
}

\section{Aminoglycoside-induced ototoxicity can profoundly affect quality of life}

Aminoglycosides cause toxicity of the vestibular (balance) or cochlear (hearing) systems of the inner ear in up to $10 \%$ of patients receiving these drugs intravenously. ${ }^{1}$ Frequently permanent, toxicity can result in failure to return to work and diminished quality of life. ${ }^{2}$ Gentamicin, tobramycin and streptomycin are preferentially vestibulotoxic, whereas amikacin and kanamycin are primarily cochleotoxic. ${ }^{1,2}$ Ototoxicity may develop with the use of ear drops, particularly in the presence of tympanic membrane perforation or tympanostomy tubes. ${ }^{3}$ In this situation, alternative antimicrobial drops should be selected.
Discontinuation of aminoglycoside therapy at the earliest recognition of ototoxicity may reduce the extent of impairment

Delays in the diagnosis of ototoxicity occur even when patients report symptoms to their physician. ${ }^{6}$ Cochleotoxicity presents with hearing impairment. Vestibulotoxicity typically manifests with ataxia, dysequilibrium and oscillopsia (visual blurring with head movement), which should be elicited on history taking. ${ }^{1,2,6}$ Vertigo is usually absent, because aminoglycoside-induced toxicity causes symmetric bilateral vestibular loss. ${ }^{1}$ Appropriate questioning is needed to ensure early detection and prompt discontinuation of therapy. ${ }^{1,2}$

\section{References}

1. Ariano RE, Zelenitsky SA, Kassum DA. Aminoglycoside-induced vestibular injury: maintaining a sense of balance. Ann Pharmacother 2008;42: 1282-9.

2. Black FO, Pesznecker S, Stallings V. Permanent gentamicin vestibulotoxicity. Otol Neurotol 2004; 25:559-69.

3. Marais J, Rutka JA. Ototoxicity and topical ear drops. Clin Otolaryngol 1998;23:360-7.

4. Zahar JR, Rioux C, Girou E, et al. Inappropriate prescribing of aminoglycosides: risk factors and

\section{Normal laboratory monitoring may provide false reassurance}

Ototoxicity may develop in patients with normal renal function and in the presence of recommended target drug levels. ${ }^{6}$ Although prospective trials showing efficacy are lacking, additional monitoring should be considered for patients receiving more than seven days of treatment. ${ }^{1,2,5,6}$ Cochleotoxicity may be detected with high-frequency audiometry. For patients in hospital, dynamic visual acuity testing may be used to detect vestibulotoxicity at the bedside (Appendix 1, available at www.cmaj.ca /lookup/suppl/doi:10.1503/cmaj.140339 /-/DC1).

impact of an antibiotic control team. $J$ Antimicrob Chemother 2006;58:651-6.

5. Berringer R. Aminoglycoside therapy: balancing risk versus benefit [R10814E]. Ottawa: Canadian Medical Protective Association; 2008. Available: https://oplfrpd5.cmpa-acpm.ca/-/aminoglycoside -therapy-balancing-risk-versus-benefit (accessed 2014 Aug. 22).

6. Ahmed RM, Hannigan IP, MacDougall HG, et al. Gentamicin ototoxicity: a 23-year selected case series of 103 patients. Med J Aust 2012;196:701-4.

\section{Aminoglycoside-induced ototoxicity is often preventable}

Prospective audits have shown that patients are frequently prescribed aminoglycosides without indication, when safer treatment options exist or for unnecessarily prolonged durations. ${ }^{4}$ Risk of ototoxicity increases with total cumulative exposure. ${ }^{1,2}$ When aminoglycoside therapy is indicated, the duration of therapy should be minimized. ${ }^{4,5}$

Patients must be counselled regarding the risks and benefits of aminoglycoside therapy

In Canada, legal actions resulting from aminoglycoside-induced ototoxicity are twice as likely to settle in favour of the plaintiff compared with all other actions. ${ }^{5}$ Issues related to informed consent are raised in most cases. In the absence of safer alternatives, efforts should be made to minimize the duration of treatment and concurrent use of other ototoxic medications and to educate patients about early recognition of symptoms., ${ }^{4,5}$

\section{Competing of interests: None declared.}

This article has been peer reviewed.

Affiliations: Division of Infectious Diseases (Leis, Gold), Department of Medicine; Centre for Quality Improvement and Patient Safety (Leis); Department of Otolaryngology - Head and Neck Surgery (Rutka), University of Toronto, Toronto, Ont.

Correspondence to: Jerome Leis, jerome.leis @ sunnybrook.ca

CMAJ 2015. DOI:10.1503/cmaj.140339 